\title{
Marine alkaloids as the chemical marker for the prey-predator relationship of the sponge Xestospongia sp. and the nudibranch Jorunna funebris
}

\author{
Qihao $\mathrm{Wu}^{1,3} \cdot$ Song-Wei $\mathrm{Li}^{1,4} \cdot$ Nicole J. de Voogd ${ }^{5,6} \cdot$ Hong Wang $^{3} \cdot \mathrm{Li}^{-G o n g ~ Y a o}{ }^{1} \cdot$ Yue-Wei Guo ${ }^{1,2} \cdot$ Xu-Wen $\mathrm{Li}^{1,2}$
}

Received: 27 July 2020 / Accepted: 4 January 2021 / Published online: 29 March 2021

(C) The Author(s) 2021

\begin{abstract}
The dietary relationship study between marine sponge Xestospongia sp. and its nudibranch predators Jorunna funebris based on the discovery of isoquinolinequinones has long been studied. In this study, chemical investigation of the sponge Xestospongia sp. and nudibranch J. funebris from the South China Sea yielded a new marine alkaloid neopetroside C (1), together with nine known alkaloids (2-10). The chemical structures of all the compounds were elucidated by extensive spectroscopic analysis. Neopetroside C (1) featured a riboside of nicotinic acid with a rare $\alpha-N$ glycosildic linkage and an acyl residue of (Z)-2-methylbut-2-enoic acid attached to C-5'. The plausible chemical ecology relationship between sponge Xestospongia sp. and its nudibranch predator J. funebris was proposed based on the biogenetic relationship of the common marine alkaloids. The observation of two structural fragments, (Z)-2-methylbut-2-enoyloxy and trigonelline groups in both sponge and nudibranch, indicated that nudibranch might uptake chemicals from sponge and then modify and transform them into chemical weapons to defend against predators.
\end{abstract}

Keywords Marine alkaloids $\cdot$ Jorunna funebris $\cdot$ Xestospongia sp. Chemical marker

\section{Introduction}

Edited by Chengchao Chen.

Yue-Wei Guo

ywguo@simm.ac.cn

$\triangle$ Xu-Wen Li

xwli@simm.ac.cn

1 State Key Laboratory of Drug Research, Shanghai Institute of Materia Medica, Chinese Academy of Sciences, Shanghai 201203, China

2 Open Studio for Druggability Research of Marine Natural Products, Pilot National Laboratory for Marine Science and Technology (Qingdao), Qingdao 266237, China

3 College of Pharmaceutical Science and Collaborative Innovation Center of Yangtze River Delta Region Green Pharmaceuticals, Zhejiang University of Technology, Hangzhou 310014, China

4 Nanjing University of Chinese Medicine, Nanjing 210023, China

5 National Museum of Natural History, PO Box 9517, 2300 RA Leiden, Netherlands

6 Institute of Environmental Sciences, Leiden University, PO Box 9518, 2300 RA Leiden, Netherlands
In the past several decades, different species of marine sponges have been investigated for their bioactive secondary metabolites. A number of studies have indicated that marine sponges are one of the richest sources of marine natural products with potential therapeutic application (Liu et al. 2019; Wu et al. 2019a, b; Zhu et al. 2019). The marine sponges of the genus Xestospongia are widely distributed in the South China Sea. They are well known as one of the richest sources of diverse bioactive natural products, including brominated polyacetylenes (Yang et al. 2019) and alkaloids (Huang et al. 2016). Some of these metabolites have attracted the attention for their total syntheses and/or biological studies towards drug leads (Liang et al. 2014; Sun et al. 2017).

The marine nudibranchs are known to assimilate small molecules based on prey-predator relationship from other low-grade organisms such as sponges for chemical defense against harsh marine living environments (Bornancin et al. 2017; Dean and Prinsep 2017; Puglisi et al. 2019; Wu et al. 2020). The marine nudibranch Jorunna funebris (Mollusca: Gastropoda: Opisthobranchia: Nudibranchia: 
Kentrodorididae) has been proven to feed on sponge of the genus Xestospongia, by the discovery of isoquinolinequinones as the chemical marker from both nudibranch J. funebris and its sponge-prey Xestospongia sp. (Huang et al. 2016). As part of our ongoing project on searching for novel bioactive compounds from Hainan marine sponges (Han et al. 2018; Huang et al. 2016; Wu et al. 2019a, b; Xue et al. 2017; Yang et al. 2019) and the chemical ecology study between sponges and their nudibranch predator, we made a collection of the sponge Xestospongia sp. and its possible nudibranch predator J. funebris from the same location (Xidao Island, Hainan Province). In this paper, we described the discovery of 10 marine alkaloids, as well as the dietary relationship between the sponge Xestospongia sp. and its predator $J$. funebris based on those marine alkaloids.

\section{Results}

Chemical investigation of the sponge Xestospongia sp. and two nudibranchs $J$. funebris led to the isolation of a previously unreported pyridine nucleoside (1) along with nine known alkaloids (2-10) (Fig. 1). Herein, we describe the isolation, structure elucidation, and their possible biosynthetic origin influenced by a prey-predator relationship.

The frozen title sponge (Xestospongia sp.) was cut into pieces and exhaustively extracted by acetone. The $n$-butanolsoluble portion of the acetone extract was chromatographed repeatedly over MCI and RP-HPLC to yield 1-4 (Fig. 1). The $\mathrm{Et}_{2} \mathrm{O}$-soluble portion of the acetone extract was repeatedly purified on column chromatography $(\mathrm{CC})$ of silica gel, Sephadex LH-20, reversed-phase-C18 (RP-C18) and RPHPLC to afford $\mathbf{9}$ and $\mathbf{1 0}$ (Fig. 1). Among them, the known compounds were readily identified as neopetroside A (2) (Shubina et al. 2015), 5-(methoxycarbonyl)tubercidin (3) (Wang et al, 2016), 1,3-dimethylisoguaninium (4) (Jeong et al. 2003), 7-methoxy-1,6-dimethyl-5,8-dihydroisoquinoline-5,8-dione (9) (Suwanborirux et al. 2003), and mimosamycin (10) (Kesteleyn and Kimpe 2000) by comparison of their NMR spectroscopic data and optical rotation with those reported in the literature.

The frozen animals J. funebris were cut into pieces and exhaustively extracted by acetone. For collection A (No. $14 \mathrm{X}-219$ collected in 2014), the $n$-butanol-soluble portion of the acetone extract was repeatedly chromatographed to yield pure compounds 5-7. For collection B (No. 18XD-200,

Compounds from sponge Xestospongia sp.<smiles>[3H]c1ccn(C2OC(COC(=O)C(C)=CC)C(O)C2O)c1</smiles>

1<smiles></smiles>

2

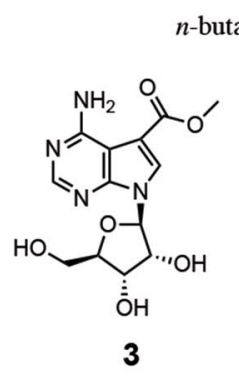

n-butanol-soluble portion

Compounds from nudibranch J. funebris (collection A)

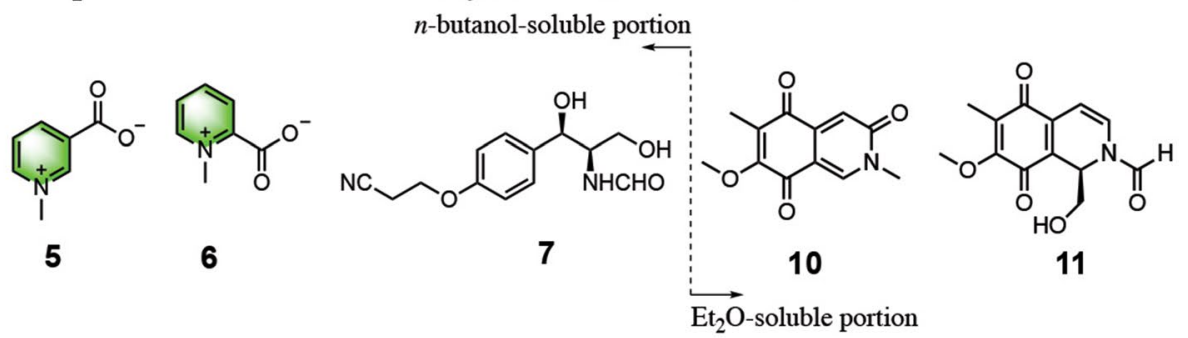<smiles>[R2]C(=O)C(=O)OCC1C2C(=O)C(OC)=C(C)C(=O)C2=CCN1C=O</smiles><smiles>COC1=C(C)C(=O)c2c(ccnc2CO)C1=O</smiles>

13

Compounds from nudibranch J. funebris (collection B)<smiles>CC(C)=CC(=O)OCc1nccc2c1C(=O)C(C)=C(O)C2=O</smiles><smiles>COC(=O)C1C(=O)C(C)=Cc2ccnc(C)c21</smiles>

9<smiles>CCOCCOCCOCCOCCOC</smiles>

Fig. 1 Chemical structures of compounds 1-13. Compounds 1-10 were reported in this paper, compounds 11-13 were reported previously (Huang et al. 2016). The moieties are marked in the same color among all the compounds 
collected in 2018), the $\mathrm{Et}_{2} \mathrm{O}$-soluble portion of the acetone extract gave 8-10. The known compounds were identified as trigonelline (5) (Poulin et al. 2018), homarine (6) (Poulin et al. 2018), bursatellin (7) (Cimino et al. 1987), $O$-demethylrenierone (8) (Plubrukarn et al. 2003), 7-methoxy1,6-dimethyl-5,8-dihydroisoquinoline-5,8-dione (9) (Suwanborirux et al. 2003), and mimosamycin (10) (Kesteleyn and Kimpe 2000).

Neopetroside C (1) was obtained as a brown amorphous solid, $[\alpha]+66(c 0.1, \mathrm{MeOH})$. Its molecular formula, $\mathrm{C}_{16} \mathrm{H}_{19} \mathrm{NO}_{7}$, was established by HRESIMS $(\mathrm{m} / \mathrm{z} 338.1240$, $[\mathrm{M}+\mathrm{H}]^{+}$, calcd for $\mathrm{C}_{16} \mathrm{H}_{20} \mathrm{NO}_{7}, 338.1234$ ), indicating eight degrees of unsaturation. The ${ }^{13} \mathrm{C}$ NMR spectrum displayed 16 carbon signals which, in combination with DEPT and HSQC spectra, can be categorized as two methyls, one $\mathrm{sp}^{3}$ methylene, four $\mathrm{sp}^{3}$ methines, five $\mathrm{sp}^{2}$ methines, four $\mathrm{sp}^{3}$ quaternary carbons. Detailed analysis of spectroscopic data of compound 1 revealed the presence of a ribose moiety $\left(\delta_{\mathrm{H}}\right.$ $4.36, \delta_{\mathrm{H}} 4.48, \delta_{\mathrm{C}} 64.3, \mathrm{CH}_{2} ; \delta_{\mathrm{H}} 6.47, \delta_{\mathrm{C}} 98.0, \mathrm{CH} ; \delta_{\mathrm{H}} 4.76$, $\left.\delta_{\mathrm{C}} 73.6, \mathrm{CH} ; \delta_{\mathrm{H}} 4.28, \delta_{\mathrm{C}} 72.6, \mathrm{CH} ; \delta_{\mathrm{H}} 4.90, \delta_{\mathrm{C}} 87.3, \mathrm{CH}\right)$ (Shubina et al. 2015), the signals of the carbons and protons of the aromatic ring $\left(\delta_{\mathrm{H}} 9.27, \delta_{\mathrm{C}} 143.7, \mathrm{CH} ; \delta_{\mathrm{C}} 138.6, \mathrm{qC}\right.$; $\delta_{\mathrm{H}} 8.95, \delta_{\mathrm{C}} 147.3, \mathrm{CH} ; \delta_{\mathrm{H}} 8.07, \delta_{\mathrm{C}} 127.2, \mathrm{CH} ; \delta_{\mathrm{H}} 8.94, \delta_{\mathrm{C}}$ $143.1, \mathrm{CH})$, and two downfield quaternary carbons at $\delta_{\mathrm{C}}$ 167.1 and 168.7 (Table 1).

The above structural features were reminiscent of cooccurring neopetroside A (2), which was firstly isolated from the sponge of the genus Neopetrosia (Shubina et al. 2015). A careful comparison of the NMR data of these two compounds revealed that they differed only by the substitution at C-5' (Fig. 1). The remaining signals of one trisubstituted double bond $\left(\delta_{\mathrm{H}} 6.19, \delta_{\mathrm{C}} 140.2, \mathrm{CH} ; \delta_{\mathrm{C}} 128.6, \mathrm{qC}\right)$ and two methyls $\left(\delta_{\mathrm{H}} 1.95, \delta_{\mathrm{C}} 20.7, \mathrm{CH}_{3} ; \delta_{\mathrm{H}} 2.01, \delta_{\mathrm{C}} 16.1, \mathrm{CH}_{3}\right)$ were then assigned as a (Z)-2-methylbut-2-enoate moiety, which was determined by the presence of a HMBC crosspeak between Me-5" and H-3". It was further supported by comparing the spectroscopic data with those reported in the literature for (Z)-2-methylbut-2-enoyloxy-containing natural products (Plubrukarn et al. 2003). The HMBC correlations of the methylene protons $\mathrm{H}_{2}-5^{\prime}$ to the carbonyl C-1" indicated that the (Z)-2-methylbut-2-enoyloxy group was attached to C-5' of the sugar moiety in $\mathbf{1}$. On the basis of the above findings, the planar structure of $\mathbf{1}$ was fully established (Fig. 2). The structure of $\mathbf{1}$ was further confirmed by ESI-MS $^{n}$ analysis, showing fragmentations with the loss of functional groups. The yielded ESI-MS ${ }^{n}$ ion peaks of neopetroside C (1) were analyzed and fully assigned as shown in Fig. 3.

The configuration of the ribofuranoside ring in $\mathbf{1}$ was also determined to be the same as co-occurring 2 by careful interpretation of its NOESY spectrum, with the clear NOE correlations of $\mathrm{H}-1^{\prime} / \mathrm{H}-3^{\prime}, \mathrm{H}_{2}-5^{\prime}$ and $\mathrm{H}-4^{\prime} / \mathrm{H}-2, \mathrm{H}-6$ (Fig. 2). Since the absolute configuration of $\mathbf{2}$ has been previously
Table $1{ }^{1} \mathrm{H}(500 \mathrm{MHz})$ and ${ }^{13} \mathrm{C}$ NMR $(125 \mathrm{MHz})$ data $(\delta$ in ppm, type) of $\mathbf{1}^{\mathrm{a}}$ and $\mathbf{2}^{\mathrm{b}}$ recorded in $\mathrm{CD}_{3} \mathrm{OD}$

\begin{tabular}{|c|c|c|c|c|}
\hline \multirow[t]{2}{*}{ No. } & \multicolumn{2}{|l|}{1} & \multicolumn{2}{|l|}{2} \\
\hline & $\delta_{\mathrm{H}}$ mult $(J$ in $\mathrm{Hz})$ & $\delta_{\mathrm{C}}$ & $\delta_{\mathrm{H}}$ mult $(J$ in $\mathrm{Hz})$ & $\delta_{\mathrm{C}}$ \\
\hline 2 & $9.27 \mathrm{~s}$ & $143.7 \mathrm{CH}$ & $9.28 \mathrm{~s}$ & $144.3 \mathrm{CH}$ \\
\hline 3 & - & $138.6 \mathrm{qC}$ & - & $139.5 \mathrm{CH}$ \\
\hline 4 & $8.94 \mathrm{~d}(7.0)$ & $147.3 \mathrm{CH}$ & $8.94 \mathrm{dd}(8.0,1.4)$ & $147.9 \mathrm{CH}$ \\
\hline 5 & $8.07 \mathrm{t}(7.0)$ & $127.2 \mathrm{CH}$ & $8.06 \mathrm{dd}(8.0,6.2)$ & $127.8 \mathrm{CH}$ \\
\hline 6 & $8.95 \mathrm{dd}(7.0)$ & $143.1 \mathrm{CH}$ & $8.96 \mathrm{dd}(6.2,1.4)$ & $143.7 \mathrm{CH}$ \\
\hline 7 & - & $167.1 \mathrm{qC}$ & - & $167.2 \mathrm{qC}$ \\
\hline $1^{\prime}$ & $6.47 \mathrm{~d}(5.5)$ & $98.0 \mathrm{CH}$ & $6.50 \mathrm{~d}(5.3)$ & $98.6 \mathrm{CH}$ \\
\hline $2^{\prime}$ & $4.76 \mathrm{t}(4.5)$ & $73.6 \mathrm{CH}$ & $4.79 \mathrm{~m}$ & $74.4 \mathrm{CH}$ \\
\hline $3^{\prime}$ & $4.28 \mathrm{dd}(4.5,3.5)$ & $72.6 \mathrm{CH}$ & $4.33 \mathrm{dd}(3.8,4.5)$ & $73.3 \mathrm{CH}$ \\
\hline $4^{\prime}$ & $4.90 \mathrm{dt}(4.5,3.5)$ & $87.3 \mathrm{CH}$ & $\begin{array}{l}4.96 \text { ddd }(3.8,3.6 \text {, } \\
4.6)\end{array}$ & $88.0 \mathrm{CH}$ \\
\hline $5^{\prime} \mathrm{a}$ & $4.36 \mathrm{dd}(12.0,4.5)$ & $64.3 \mathrm{CH}_{2}$ & $4.50 \mathrm{dd}(4.6,12.2)$ & $65.3 \mathrm{CH}_{2}$ \\
\hline $5^{\prime} \mathrm{b}$ & $4.48 \mathrm{dd}(12.0,3.5)$ & & $4.59 \mathrm{dd}(3.6,12.2)$ & \\
\hline $1^{\prime \prime}$ & - & $168.7 \mathrm{qC}$ & - & $122.3 \mathrm{qC}$ \\
\hline $2^{\prime \prime}$ & - & $128.6 \mathrm{qC}$ & 7.93, d (8.8) & $133.6 \mathrm{CH}$ \\
\hline $3^{\prime \prime}$ & $6.19 \mathrm{qq}(7.5,1.5)$ & $140.2 \mathrm{CH}$ & $6.68, \mathrm{~d}(8.8)$ & $117.0 \mathrm{CH}$ \\
\hline $4^{\prime \prime}$ & $2.01 \mathrm{dq}(7.5,1.5)$ & $16.1 \mathrm{CH}_{3}$ & - & $164.5 \mathrm{qC}$ \\
\hline $5^{\prime \prime}$ & 1.95 quint (1.5) & $20.7 \mathrm{CH}_{3}$ & $6.68, \mathrm{~d}(8.8)$ & $117.0 \mathrm{CH}$ \\
\hline $6^{\prime \prime}$ & - & - & 7.93, d (8.8) & $133.6 \mathrm{CH}$ \\
\hline $7^{\prime \prime}$ & - & - & - & $168.2 \mathrm{qC}$ \\
\hline
\end{tabular}

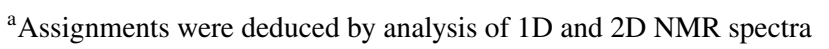
${ }^{\mathrm{b}}$ Chemical shifts of $\mathbf{2}$ were reported in the reference (Shubina et al. 2015)

determined by total synthesis, from a biogenetic point of view, bearing in mind the same signs of the $[\alpha]_{D}$ values of $\mathbf{1}$ (+66) and $\mathbf{2}(+20)$ (Shubina et al. 2015), the absolute configuration of compound $\mathbf{1}$ was assigned as $1^{\prime} S, 2^{\prime} R, 3^{\prime} S, 4^{\prime} R$.

\section{Discussion}

In this study, a chemical investigation of the two title animals resulted in the establishment of a dietary relationship between nudibranch J. funebris and its sponge-prey Xestospongia sp. As shown in Fig. 4, by careful comparison of the alkaloids in two nudibranch individuals (collections $\mathrm{A}$ and B from the same location in 2014 and 2018, respectively) with those in the sponge Xestospongia sp., several common alkaloids or related structural fragments were observed in J. funebris nudibranch and Xestospongia sp. sponge. To be more specific, common isoquinoline alkaloids ( 9 and 10) were identified from the $\mathrm{Et}_{2} \mathrm{O}$ portions of both $J$. funebris (10 for collection A; 9 and $\mathbf{1 0}$ for collection B) and Xestospongia sp., whereas only one alkaloid (8) was found in $J$. funebris (collection A). Two rare naturally occurring ribosides (1 and 2) as well as their structural fragments (5) were 

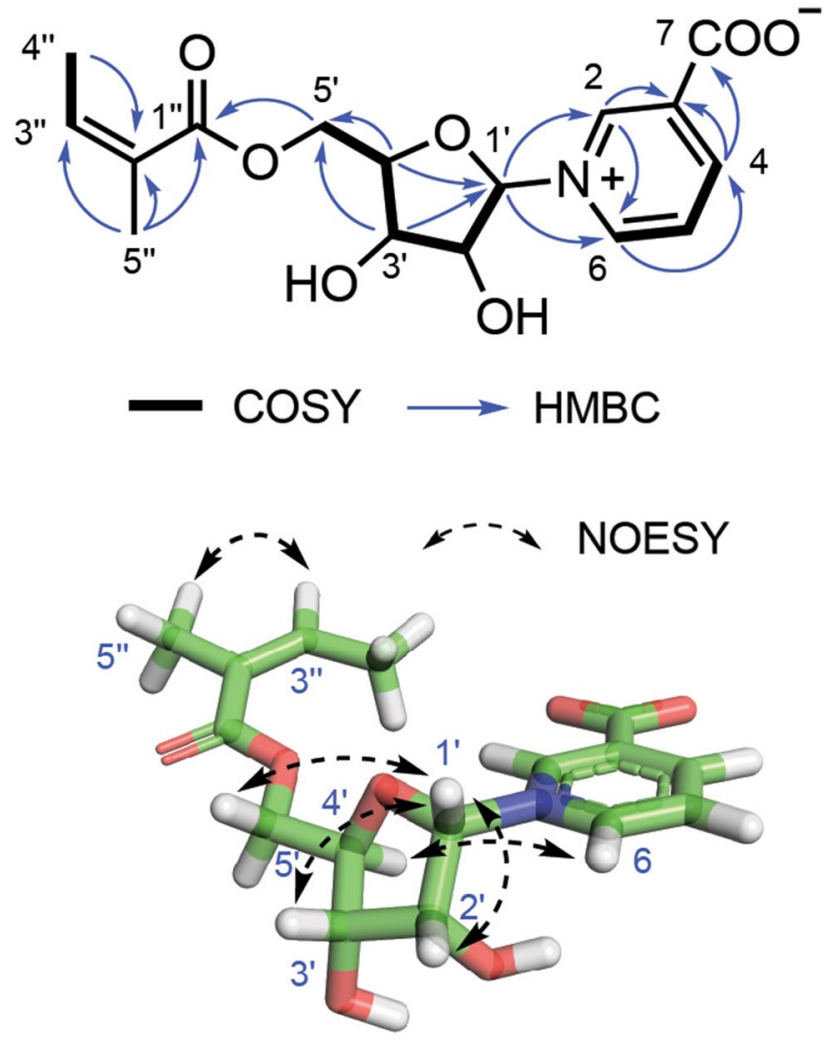

Fig. $2{ }^{1} \mathrm{H}^{-1} \mathrm{H}$ COSY, key HMBC, and NOESY correlations of compound 1

discovered from the $n$ - $\mathrm{BuOH}$ portions of Xestospongia sp. and $J$. funebris (collection B), respectively. In addition, the (Z)-2-methylbut-2-enoyloxy group was observed in $\mathbf{1 , 8}$ and 12. On the basis of these observations, we thus hold the belief that the nudibranch J. funebris could accumulate and/ or biotransform the sponge-derived metabolites, especially those toxic isoquinolinequinone alkaloids, as its own chemical defensive agents for surviving in the harsh marine living environment. Moreover, it is obvious that the nudibranch J. funebris can feed on more than one sponge, such as the aforementioned Xestospongia sp., to acquire structurally diverse alkaloid metabolites to apply them as the chemical weapons on different occasions. In turn, such structurally characteristic alkaloids could act as chemical marker to uncover the prey-predator relationship of marine mollusks and sponges.

More intriguingly, to explain the dietary expansion of $J$. funebris in Xidao Island water, an extensive literature search revealed that they may selectively acquire some chemicals from sponges Xestospongia sp. to protect themselves from their own predators, the mud crabs. As reported by Dr. Kubanek and her colleagues (Poulin et al. 2018), trigonelline (5) and homarine (6) in blue crabs' urine induce fear in mud crabs. Thus, we speculated that the J. funebris has evolved to use those chemicals to scare mud crabs away. The accumulation of $\mathbf{5}$ and $\mathbf{6}$ in J. funebris is possibly from a direct dietary relationship since trigonelline and homarine occur in many plants, such as algae (Gebser and Pohnert 2013). However, no such direct evidence has shown that J. funebris feed on algae. Back to the compounds, we isolated from the sponge Xestospongia sp., the unexpected metabolites $\mathbf{1}$ and $\mathbf{2}$ might be the real sources of trigonelline and homarine. The nudibranch selectively ingests Xestospongia sp., generating $\mathbf{5}$ and $\mathbf{6}$, by digesting neopetrosides (1 and $\mathbf{2}$ ).

\section{Conclusions}

In summary, the chemical investigation on one sponge Xestospongia $\mathrm{sp}$. and the nudibranch J. funebris led to the isolation and identification of ten alkaloids with high chemical diversity. The discovery of one previously unreported compound, namely, neopetroside C (1), featured an extremely rare $\alpha-N$ glycosidic linkage with a nicotinic acid moiety, has added to an extremely diverse and complex array of marine alkaloids which are rapidly expanding. The structures of these compounds, including relative stereochemistry, were elucidated by a combination of detailed spectroscopic analyses and by the comparison of spectroscopic data with those reported in the literature. The absolute configuration of the new metabolite (1) was tentatively assigned based on the biogenetic consideration and comparison of its NMR data and optical rotation value with those of the related model compound (2). In the future, more chemical ecological research based on predator-prey relationship is crucial to further prove our hypothesis as to the genuine biogenetic relationship of these alkaloids. Further extensive evaluation of the biological activity of these compounds would also be crucial in identifying their pharmacological application.

\section{Materials and methods}

\section{General experimental procedures}

Optical rotations of all the isolates were measured in methanol on a Perkin-Elmer 241MC polarimeter. IR spectrum of 1 was recorded on a Nicolet 6700 spectrometer with $\mathrm{KBr}$ pellets. NMR spectra (1D and 2D NMR) were measured on a Bruker DRX-400 and Bruker DRX-500 spectrometer, using the residual methanol signal at $\delta_{\mathrm{H}} 3.31 \mathrm{ppm}$ and $\delta_{\mathrm{C}}$ $49.00 \mathrm{ppm}$ as an internal standard for ${ }^{1} \mathrm{H}$ NMR and ${ }^{13} \mathrm{C}$ NMR, respectively. HR-ESI-MS spectrum of $\mathbf{1}$ was recorded on Agilent G6250 Q-TOF. Reversed-phase HPLC purification was carried out on an Agilent 1260 series liquid 


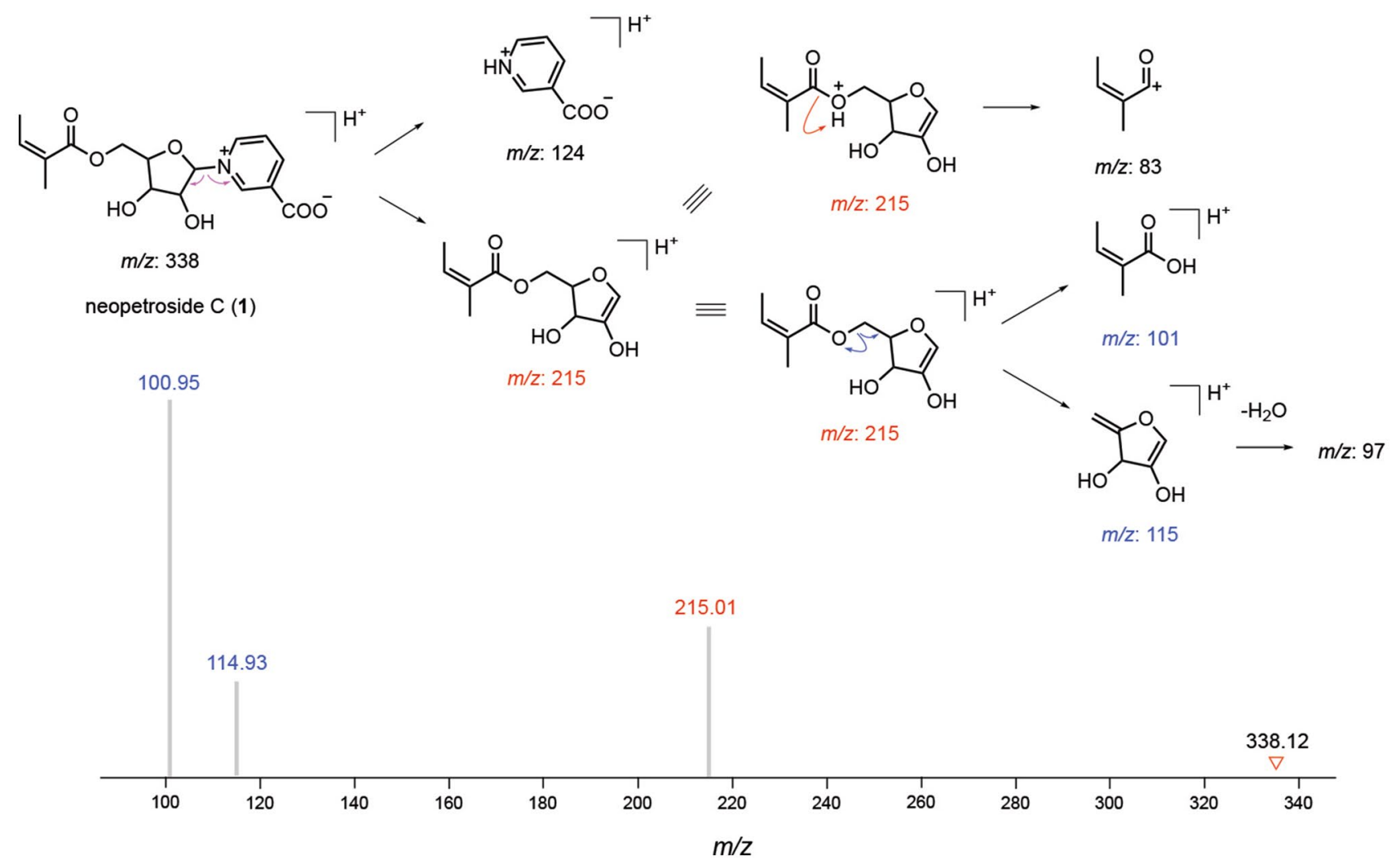

Fig. 3 Observed product ions during $\mathrm{MS}^{n}$ fragmentation experiments of compound $\mathbf{1}$ and assignment of the molecular ion peaks

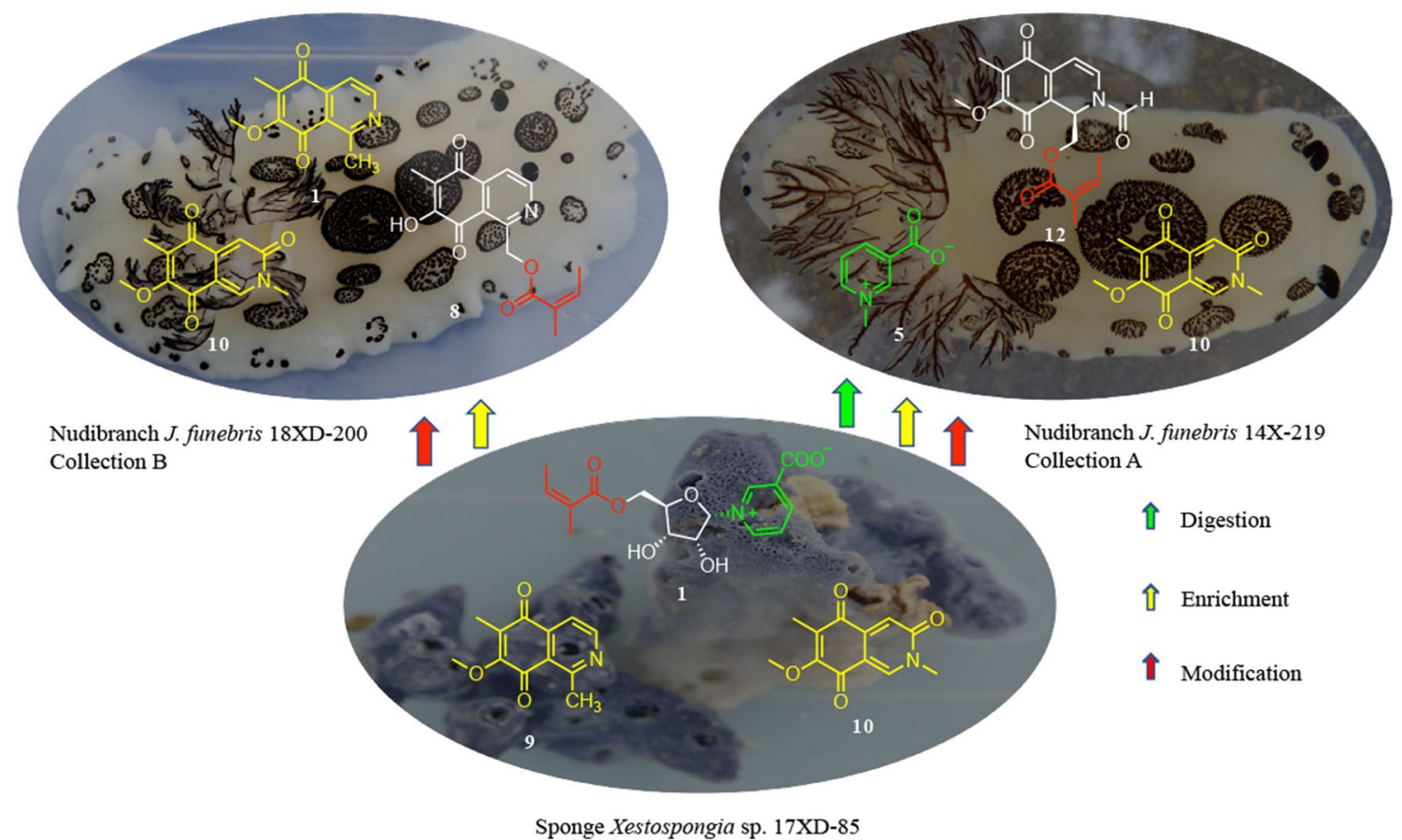

Fig. 4 Dietary relationship between nudibranch J. funebris and sponge Xestospongia sp. uncovered by neopetrosides and isoquinolines as characteristic chemical markers 
chromatography with a semi-preparative ODS-HG-5 column $(5 \mu \mathrm{m}, 250 \times 9.4 \mathrm{~mm})$. Silica gel and precoated silica gel plates were used for column chromatography and analytical TLC, respectively. All the chemicals used in this research were obtained from commercial sources. All solvents used for column chromatography were of analytical grade, and solvents used for HPLC were of HPLC grade.

\section{Biological material, extraction and isolation}

\section{Biological material}

The molluscs and sponges were collected by scuba diving at Xidao Island, Hainan Province, China, at a depth of 15-20 m, and identified by Professor Nicole J. de Voogd. For sponges, samples were collected in May 2017, while molluscs (collections A and B) were collected in May 2014 and May 2018, respectively. The voucher samples are deposited at the Shanghai Institute of Materia Medica, CAS.

\section{Extraction and isolation of 1-10}

The lyophilized bodies of sponges Xestospongia sp. (dry weight $250 \mathrm{~g}$ ) were cut into pieces and exhaustively extracted by acetone $(20.0 \mathrm{~g})$. The $n$-butanol-soluble portion of the acetone extract $(6.1 \mathrm{~g})$ was chromatographed repeatedly over MCI and RP-HPLC to yield 1-4. The $\mathrm{Et}_{2} \mathrm{O}$-soluble portion of the acetone extract $(8.0 \mathrm{~g})$ was repeatedly purified on repeated column chromatography (CC) of silica gel, Sephadex LH-20, RP-C18 CC and RP-HPLC to afford compounds $\mathbf{9}$ and $\mathbf{1 0}$.

The frozen animals J. funebris (dry weight $3.5 \mathrm{~g}$ for collection A and dry weight $3.7 \mathrm{~g}$ for collection B) were cut into pieces and exhaustively extracted by acetone $(0.6 \mathrm{~g}$ acetone extract for collection $\mathrm{A}$ and $0.7 \mathrm{~g}$ acetone extract for collection B). For collection A (No. 14X-219 collected in May 2014), the $n$-butanol-soluble portion of the acetone extract $(0.3 \mathrm{~g})$ was repeatedly chromatographed by RP-C18 $\mathrm{CC}$ and RP-HPLC to yield 5-7. The chemical investigation of $\mathrm{Et}_{2} \mathrm{O}$-soluble portion has been reported before (Huang et al. 2016). For collection B (No. 18XD-200, collected in 2018), the $\mathrm{Et}_{2} \mathrm{O}$-soluble portion of the acetone extract gave 8-10. Chemical investigation of its $n$-butanol-soluble portion failed to isolate any pure compounds.

Neopetroside $C(\mathbf{1})$, brown amorphous solid, $[\alpha]+66$ (c $0.1, \mathrm{MeOH}$ ); for ${ }^{1} \mathrm{H}$ and ${ }^{13} \mathrm{C}$ NMR spectroscopic data (Table 1); HR-ESI-MS: $m / z$ calcd for $\mathrm{C}_{16} \mathrm{H}_{20} \mathrm{NO}_{7}[\mathrm{M}+\mathrm{H}]^{+}$: 338.1234; found: 338.1240. See Supplementary Figures $\mathrm{S} 1-\mathrm{S} 11$ in the supplementary document for all the spectra of compound $\mathbf{1}$.

Supplementary Information The online version contains supplementary material available at https://doi.org/10.1007/s42995-021-00096-w.
Acknowledgements This research work was financially supported by the National Natural Science Foundation of China (NSFC) (Nos. 8202290170, 81991521, 42076099, 41676073), the NSFC/CNRS joint project (No. 81811530284), and the SKLDR/ SIMM Project (No. SIMM1903ZZ-04). X-W Li is also thankful for the Shanghai Rising-Star Program (No. 20QA1411100) and SA-SIBS Scholarship Program. We thank Dr. S-Q Zhang and Dr. L Gong from Institute of Oceanology, CAS, for the kind help of taxonomic identification on the animal material.

Author contributions QW conducted the chemical investigation experiment of the sponge and did the structure elucidation and chemical ecological analysis; S-WL conducted the chemical investigation experiment of the mollusk; NJdV identified the species of the animal samples; HW helped the structure elucidation part; L-GY collected the animal samples from the Sea; Y-WG designed part of the research and revised the paper; X-WL designed part of the research, did the chemical ecological analysis and wrote the paper.

\section{Compliance with ethical standards}

Conflicts of interest All the authors declare that they have no conflict of interest and no competing financial interest.

Animal and human rights statement This article does not contain any studies with human participants or animals performed by any of the authors.

Open Access This article is licensed under a Creative Commons Attribution 4.0 International License, which permits use, sharing, adaptation, distribution and reproduction in any medium or format, as long as you give appropriate credit to the original author(s) and the source, provide a link to the Creative Commons licence, and indicate if changes were made. The images or other third party material in this article are included in the article's Creative Commons licence, unless indicated otherwise in a credit line to the material. If material is not included in the article's Creative Commons licence and your intended use is not permitted by statutory regulation or exceeds the permitted use, you will need to obtain permission directly from the copyright holder. To view a copy of this licence, visit http://creativecommons.org/licenses/by/4.0/.

\section{References}

Bornancin L, Bonnard I, Mills SC, Banaigs B (2017) Chemical mediation as a structuring element in marine gastropod predator-prey interactions. Nat Prod Rep 34:644-676

Cimino G, Gavagnin M, Sodano G, Spinella A, Strazzullo G, Schmitz FJ, Yalamanchili G (1987) Revised structure of bursatellin. J Org Chem 52:2301-2303

Dean LJ, Prinsep MR (2017) The chemistry and chemical ecology of nudibranchs. Nat Prod Rep 34:1359-1390

Gebser B, Pohnert G (2013) Synchronized regulation of different zwitterionic metabolites in the osmoadaption of phytoplankton. Mar Drugs 11:2168-2182

Han GY, Sun DY, Liang LF, Yao LG, Chen KX, Guo YW (2018) Spongian diterpenes from Chinese marine sponge Spongia officinalis. Fitoterapia 127:159-165

Huang RY, Chen WT, Kurtán T, Mándi A, Ding J, Li J, Li XW, Guo YW (2016) Bioactive isoquinolinequinone alkaloids from the South China Sea nudibranch Jorunna funebris and its spongeprey Xestospongia sp. Future Med Chem 8:17-27 
Jeong SJ, Inagaki M, Higuchi R, Miyamoto T, Ono M, Kuwano M, Van Soest RW (2003) 1,3-Dimethylisoguaninium, an antiangiogenic purine analog from the sponge Amphimedon paraviridis. Chem Pharm Bull 51:731-733

Kesteleyn B, De Kimpe N (2000) Synthesis of mimosamycin. J Org Chem 65:635-639

Liang LF, Wang T, Cai YS, He WF, Sun P, Li YF, Huang Q, Taglialatela-Scafati O, Wang HY, Guo YW (2014) Brominated polyunsaturated lipids from the Chinese sponge Xestospongia testudinaria as a new class of pancreatic lipase inhibitors. Eur J Med Chem 79:290-297

Liu L, Zheng YY, Shao CL, Wang CY (2019) Metabolites from marine invertebrates and their symbiotic microorganisms: molecular diversity discovery, mining, and application. Mar Life Sci Technol 1:60-94

Plubrukarn A, Yuenyongsawad S, Thammasaroj T, Jitsue A (2003) Cytotoxic isoquinoline quinones from the Thai sponge Cribrochalina. Pharm Biol 41:439-442

Poulin RX, Lavoie S, Siegel K, Gaul DA, Weissburg MJ, Kubanek J (2018) Chemical encoding of risk perception and predator detection among estuarine invertebrates. Proc Natl Acad Sci 115:662-667

Puglisi MP, Sneed JM, Ritson-Williams R, Young R (2019) Marine chemical ecology in benthic environments. Nat Prod Rep 36:410-429

Shubina LK, Makarieva TN, Yashunsky DV, Nifantiev NE, Denisenko VA, Dmitrenok PS, Dyshlovoy SA, Fedorov SN, Krasokhin VB, Jeong SH, Han J, Stonik VA (2015) Pyridine nucleosides neopetrosides A and B from a marine Neopetrosia sp. sponge. Synthesis of neopetroside $\mathrm{A}$ and its $\beta$-riboside analogue. J Nat Prod 78:1383-1389

Sun DY, Han GY, Gong JX, Nay B, Li XW, Guo YW (2017) Asymmetric total synthesis of distaminolyne $A$ and revision of its absolute configuration. Org Lett 3:714-717
Suwanborirux K, Amnuoypol S, Plubrukarn A, Pummangura S, Kubo A, Tanaka C, Saito N (2003) Chemistry of renieramycins. Part 3. (1) isolation and structure of stabilized renieramycin type derivatives possessing antitumor activity from Thai sponge Xestospongia species, pretreated with potassium cyanide. J Nat Prod 66:1441-1446

Wang D, Feng Y, Murtaza M, Wood S, Mellick G, Hooper JN, Quinn RJ (2016) A grand challenge: unbiased phenotypic function of metabolites from Jaspis splendens against Parkinson's disease. J Nat Prod 79:353-361

Wu Q, Chen WT, Li SW, Ye JY, Huan XJ, Gavagnin M, Yao LG, Wang H, Miao ZH, Li XW, Guo YW (2019a) Cytotoxic nitrogenous terpenoids from two South China Sea nudibranchs Phyllidiella pustulosa, Phyllidia coelestis, and their sponge-prey Acanthella cavernosa. Mar Drugs 17:56-67

Wu Q, Nay B, Yang M, Ni Y, Wang H, Yao L, Li X (2019b) Marine sponges of the genus Stelletta as promising drug sources: chemical and biological aspects. Acta Pharm Sin B 9:237-257

Wu Q, Li SW, Xu H, Wang H, Hu P, Zhang H, Luo C, Chen KX, Nay B, Guo YW, Li XW (2020) Complex polypropionates from a South China Sea photosynthetic mollusk: isolation and biomimetic synthesis highlighting novel rearrangements. Angew Chem Int Ed 59:12105-12112

Xue DQ, Liu HL, Chen SH, Mollo E, Gavagnin M, Li J, Li XW, Guo YW (2017) 5-Alkylpyrrole-2-carboxaldehyde derivatives from the Chinese sponge Mycale lissochela and their PTP1B inhibitory activities. Chin Chem Lett 28:1190-1193

Yang M, Liang LF, Yao LG, Liu HL, Guo YW (2019) A new brominated polyacetylene from Chinese marine sponge Xestospongia testudinaria. J Asian Nat Prod Res 21:573-578

Zhu J, Liu Y, Liu Z, Wang H, Zhang H (2019) Bioactive nitrogenous secondary metabolites from the marine sponge genus Haliclona. Mar Drugs 17:682-694 